\title{
RENAL PELVIC STONES: CHOOSING SHOCK WAVE LITHOTRIPSY OR PERCUTANEOUS NEPHROLITHOTOMY
}

\author{
ROBERT MARCOVICH, ARTHUR D. SMITH \\ Department of Urology, Long Island Jewish Medical Center, New Hyde Park, New York, USA
}

\begin{abstract}
Introduction of minimally invasive techniques has revolutionized the surgical management of renal calculi. Extracorporeal shock wave lithotripsy and percutaneous nephrolithotomy are now both well-established procedures. Each modality has advantages and disadvantages, and the application of each should be based on well-defined factors. These variables include stone factors such as number, size, and composition; factors related to the stone's environment, including the stone's location, spatial anatomy of the renal collecting system, presence of hydronephrosis, and other anatomic variables, such as the presence of calyceal diverticula and renal anomalies; and clinical or patient factors like morbid obesity, the presence of a solitary kidney, and renal insufficiency. The morbidity of each procedure in relation to its efficacy should be taken in to account. This article will review current knowledge and suggest an algorithm for the rational management of renal calculi with shock wave lithotripsy and percutaneous nephrolithotomy.
\end{abstract}

Key words: kidney; kidney calculi; lithotripsy; nephrolithotomy; percutaneous; shock wave lithotripsy Int Braz J Urol. 2003; 29: 195-207

\section{INTRODUCTION}

Perhaps in no other field of surgery has the treatment of a condition changed so dramatically, and in such a short period of time, as in the surgical treatment for nephrolithiasis. The last 25 years have seen a remarkable shift from open procedures, such as nephrolithotomy and ureterolithotomy, to endourological approaches, including shock wave lithotripsy (SWL), ureteroscopy (URS), and percutaneous nephrolithotomy (PNL). Recent data from the Center for Medicare and Medicaid Services (CMS), a United States government agency which oversees payment to physicians and health care organizations for patients age 65 and older, bears out the dramatic shift. In the past decade, Medicare claims for open stone procedures have dropped $74 \%$, while those for PNL have gone up 53\% in just the last half of the decade (1). Shockwave lithotripsy is currently the single, most-commonly performed urological procedure in the US, and over the past decade the total number of SWL claims in the CMS database has increased by $37 \%$ (1).

While it is clear that endourology now constitutes the contemporary paradigm for surgical stone therapy, there still exist areas of controversy with regard to choice of specific endourological modality. There has especially been an ongoing debate between proponents of shock wave lithotripsy and percutaneous nephrolithotomy. A number of clinical studies performed over the last 15 years have attempted to define the optimal therapeutic approach for a given stone, although most of these studies have been retrospective in nature. What is most important to consider, however, is that there is a rational approach to the selection of SWL or PNL. Each modality has its specific role in the treatment of nephrolithiasis. It is the purpose of this article, 
therefore, to synthesize current knowledge, and to provide guidelines which represent state-of-the-art recommendations for treatment of stones of the renal pelvis using these 2 modalities.

\section{HOW DO WE DEFINE SUCCESS?}

The optimal therapy for a particular stone is the one most likely to achieve success with the least morbidity to the patient. A lack of consensus exists among urologists regarding what constitutes successful stone therapy. Two parameters have been used in the literature: stone-free rate (SFR) and success rate. The stone-free rate is the percentage of kidneys from which all stone material has been cleared based on postoperative radiographic imaging, while success rate encompasses both patients who become stone-free as well as patients who have only clinically insignificant residual fragments (CIRF) at 3 months following SWL (2). Despite the latter definition, which was introduced because of the observation that not all fragments clear completely after SWL, there is substantial evidence that fragments which are considered clinically insignificant (i.e. $<4 \mathrm{~mm}$ in greatest dimension) may in fact bear considerable risk of becoming significant. For example, Streem et al. showed that at a mean follow-up of 23 months after SWL, up to $43 \%$ of patients with "CIRF" experienced a significant symptomatic episode or required another intervention (3). Furthermore, residual fragments can act as a nidus for further stone growth. In a study of 83 patients with CIRF of $<4$ $\mathrm{mm}$ followed for a median 40 months, Candau et al. showed that fragments increased in size in $37 \%$ of patients, and $22 \%$ required further intervention (4).

The fundamental difference between PNL and SWL is that PNL gives the surgeon control not only of fragmentation, but also of extraction, while SWL does not permit the surgeon any control over stone extraction. Theoretically, any stone is amenable to successful treatment with PNL. With SWL, the only way for the urologist to positively influence the stonefree rate is by careful patient selection. Therefore, much of this review will focus on selection factors for, and outcomes of, shock wave lithotripsy.

\section{VARIABLES IN TREATMENT SELECTION}

There are 3 categories of variables to consider when choosing a rational treatment approach to renal stones: factors related to the stone, factors related to the stone's environment, and clinical factors. Stone factors include the number of stones and their size and composition; environmental factors include the stone's location, the spatial anatomy of the renal collecting system, the presence of hydronephrosis, and other anatomic factors such as calyceal diverticula and renal anomalies. Clinical factors such as the presence of morbid obesity or a solitary kidney should also be taken into consideration. Finally, the tools available to do the job must be taken into account, especially when considering the wide variety of extracorporeal lithotriptors in use and the endourological equipment at various institutions.

\section{Stone Factors}

\section{Composition}

Stone composition should be a major consideration in choosing the treatment approach. Zhong \& Preminger studied the interactions which occurred between shockwaves and renal calculi of differing compositions, including cystine, calcium oxalate monohydrate (COM), brushite, uric acid, apatite, and struvite (Table-1) (5). They found cystine stones to have the highest fracture toughness of all of the different calculi. Cystine stones were also classified as ductile rather than brittle, indicating that when struck with a pressure wave, they tended to deform rather than crack, explaining the clinical observation that cystine stones are difficult to fragment with SWL. Cranidis et al. used SWL monotherapy on 11 renal units with cystine calculi averaging $9 \mathrm{~mm}$ in size and reported only a 54\% success rate with a mean number of $2.2 \mathrm{SWL}$ sessions per kidney using a Dornier HM-4 lithotriptor (6). In Zhong \& Preminger's study, COM stones were found to be harder than cystine stones, but had a lower fracture toughness because COM stones were of a brittle, rather than ductile, composition. Stones composed of brushite (calcium hydrogen phosphate 
Table 1 - Fracture hardness of various types of urinary calculi.

\begin{tabular}{lcc}
\hline Stone Type & Fracture Hardness $\left(\mathbf{K P a} / \mathbf{m}^{2}\right)$ & Material Type \\
\hline Cystine & 200 & Ductile \\
COM & 136 & Brittle \\
Brushite & 119 & Brittle \\
Uric Acid & 90 & Brittle \\
Apatite & 57 & Brittle \\
Struvite & 56 & Brittle \\
\hline
\end{tabular}

Adapted from Zhong $P$ and Preminger GM: J Endourol (1994) 8:263-268. kPa/m², kilopascals per meter squared; COM, calcium oxalate monohydrate.

dihydrate) have also been shown to fragment poorly with SWL (7).

For those patients who are recurrent stone formers and have undergone a prior stone analysis, stone composition is known and, therefore, can be used as part of the decision making process. For those patients who present without a previous stone analysis, determining the "a priori" composition of their current stone offers a greater challenge. In addition to simple examination of the urine for crystals, radiographic analysis of the stone may help in determining composition. Dretler \& Polykoff documented the relationship between composition and morphology for calcium oxalate stones (8), and Bon et al. took this one step further by attempting to correlate stone-free rates after SWL with radiographic appearance of the stone (9). Using multivariable regression analysis, the latter group found that stonefree rates were higher when stones were less dense than the bone of the $12^{\text {th }}$ rib or transverse process of a vertebra, and when they were determined to be subjectively rough in appearance rather than smooth. The authors also found a significant correlation between stone composition and radiographic appearance, with COM stones being smooth in $73 \%$ of cases and denser than bone in $70 \%$, while calcium oxalate dihydrate stones were rough $94 \%$ of the time and less dense than bone in $74 \%$ of cases. They reported a 79\% SWL stone-free rate with rough, less dense stones versus a 34\% SWL stone-free rate for smooth, more dense stones.

The increasing use of unenhanced helical computerized tomography (CT) for the diagnosis of upper tract urolithiasis may provide a more sensitive assessment of stone fragility than plain radiography. Helical CT has been used to accurately determine the composition of struvite, uric acid, and calcium oxalate stones "ex vivo", but there has been overlap between calcium oxalate and brushite, as well as between cystine and struvite (10). Recently, Williams et al. found that using a 1-mm slice width and bone windows improves "ex vivo" visualization of renal stone structure on CT (11). Use of these specific CT parameters in the clinical setting has not yet been reported. However, Joseph et al. published a report in which the Hounsfield attenuation of the stone at the cross-section of its greatest dimension was assessed and compared to stone clearance rates in 30 patients undergoing SWL for stones between 5 and $20 \mathrm{~mm}$ diameter. The stone clearance rate for stones of less than 500 Hounsfield units (HU) was $100 \%$, whereas clearance rates for $\mathrm{HU}$ of $500-1000$ and > 1000 were $85.7 \%$ and $54.5 \%$, respectively (12). It seems likely that continued advances in preoperative imaging will allow for more accurate pre-treatment determination of stone composition.

\section{Size}

Stone size is much easier to determine preoperatively than stone composition, and has therefore been the primary criterion used to date for treatment selection. When more than one stone is present, the stone burden can be approximated by summing the sizes of all of the calculi.

Although predominantly formed of struvite, the material with the lowest fracture toughness (5), 
staghorn calculi are the largest of stones and should be considered a contraindication to the use of SWL monotherapy. In a comparison of complete and partial staghorns treated with PNL or SWL monotherapy (Dornier HM-3), 40\% of patients with partial staghorns and $33 \%$ of patients with full staghorns treated with SWL required postoperative placement of a nephrostomy tube for obstruction, as well as multiple repeat procedures (13).

Streem et al. have advocated combination PNL and SWL "sandwich" therapy for treatment of "extensive" calculi. They reported results of 100 renal units treated with this approach, using 1 to 3 percutaneous tracts and 1 to $3 \mathrm{SWL}$ procedures per patient. The stone-free rate in this cohort at 1 month was $63 \%$, and $34 \%$ of patients experienced a complication, mainly fever or the need for a blood transfusion. Meretyk et al. performed a prospective, randomized trial comparing SWL monotherapy on a Dornier HM-3 to combination PNL/SWL in 50 kidneys with complete staghorn stones. The SFR was $74 \%$ for the combination group versus only $22 \%$ for the SWL group, and the residual stone load in patients who were not rendered stone free was much greater in the SWL group compared to the combination group. The complication rate in the SWL monotherapy group was also significantly higher (15).

Lingeman et al. compared the SFR and retreatment rates for stones $<20 \mathrm{~mm}$ and $>20 \mathrm{~mm}$ treated with PNL versus those treated with SWL on a Dornier HM-3. The SFR for stones less than $20 \mathrm{~mm}$ in size treated with SWL was $76 \%$, with a $19 \%$ retreatment rate. In comparison, the SFR for comparable stones $<20 \mathrm{~mm}$ treated with PNL was approximately $90 \%$, with $8 \%$ requiring additional treatment. For stones $>20 \mathrm{~mm}$ treated with SWL, the SFR was only $41 \%$ compared to $82 \%$ for PNL. Of these larger stones treated with SWL, 62\% required additional procedures compared $32 \%$ who initially had PNL. Although the complication rate of PNL in this study was $24 \%$ compared to only $2.6 \%$ for SWL, the majority of PNL complications were fever $>39^{\circ} \mathrm{C}$ (responsible for $11 \%$ of the PNL complications), the need for blood transfusion, and perforation of the renal pelvis (each responsible for $5.5 \%$. of the PNL complications) (16).

\section{Environmental Factors}

\section{Location}

The renal pelvis is the most favorable location for the application of shock wave lithotripsy. In an analysis of 9 published series on the treatment of 8000 stones with SWL, stone-free rates for renal pelvic stones ranged from $80 \%$ (size $<10 \mathrm{~mm}$ ) to $56 \%$ (size $>20 \mathrm{~mm}$ ). For stones less than $20 \mathrm{~mm}$ in diameter, upper pole stones were completely cleared in $59 \%$ to $72 \%$ of cases and middle calyceal calculi were cleared in 57\% to $77 \%$ of cases. Although small (less than 10 $\mathrm{mm}$ ) lower pole calculi had comparable clearance rates to small stones located elsewhere, the stone-free rates for larger stones in the lower pole were considerably less $-55 \%$ for $11-20 \mathrm{~mm}$ and only $34 \%$ for $>20 \mathrm{~mm}$ (7).

\section{Renal Collecting System Anatomy}

Due to lower clearance rates, the management of lower pole nephrolithiasis has received considerable attention over the years. Sampaio \& Aragão proposed that lower pole calyceal anatomy might impact stone clearance after SWL (17). Despite multiple subsequent studies to date, there are still no clear guidelines because of conflicting results and differing anatomic definitions. Sampaio et al. defined the lower pole infundibulopelvic angle (LIA) as the angle between the central axis of the stone-bearing minor calyx and a line running from the central axis of the proximal ureter and the central axis of the ureteropelvic junction (UPJ) (18). They showed a significantly higher stone-free rate at 3 months in patients with LIA $>90^{\circ}$ (18). Sabnis et al. defined LIA as the angle formed between the central axis of the stone-bearing minor calyx and the axis of the renal pelvis at the junction of the lower pole infundibulum, and also looked at the role of the lower pole infundibular width (LIW). This group also found that LIA $>90^{\circ}$ was associated with improved stone clearance and added that LIW $>4 \mathrm{~mm}$ had an 84\% SFR compared to LIW < $4 \mathrm{~mm}$ (SFR of 30\%) (19). Elbahnasy et al. added lower pole infundibulopelvic length (LIL) as a variable. They found that the stone-free group had 
significantly more obtuse LIA $\left(75^{\circ}\right.$ vs. $\left.51^{\circ}\right)$, wider LIW ( $9 \mathrm{~mm}$ vs $6 \mathrm{~mm}$ ), and shorter LIL ( $3.2 \mathrm{~cm}$ vs. $3.8 \mathrm{~cm}$ ); and that patients in which all 3 parameters were unfavorable (LIA $<90^{\circ}$, LIL $>3 \mathrm{~cm}$, and LIW $<5 \mathrm{~cm}$ ) had a stone-free rate of only $17 \%$. Again, a different definition of LIA was used in this study than in the previous ones (20).

A significant step towards resolving the issue of optimal treatment for lower pole stones was recently taken with the publication of the results of Lower Pole I, a multi-institutional, prospective, randomized trial of SWL and PNL for lower pole renal calculi (21). In this study 128 patients with lower calyceal stones less than $3 \mathrm{~cm}$ in greatest dimension were randomized to either SWL or PNL. Overall, SFR were $95 \%$ for PNL and $37 \%$ for SWL, and PNL was found to yield a significantly higher SFR in all groups stratified by size (Table-2). Interestingly, lower pole infundibulopelvic anatomy had no significant influence on stone free rates after SWL, although this may have been because anatomic data were available for only 38 patients, and the stone-free rate in this group was only $45 \%$. Retreatment rate and use of auxiliary procedures occurred in $31 \%$ of patients undergoing SWL, while only $10 \%$ of PNL patients required further treatment or an auxiliary procedure. As expected, SWL had a lower complication rate than PNL (12\% vs. $23 \%)$, but this was not statistically significant. There was a significant improvement in quality-of-life (QOL) scores after treatment in both groups, but no difference was found in QOL scores between the two groups. This study would seem to indicate that PNL is superior to SWL for lower pole calculi. Nevertheless, we would still be hard pressed to advocate PNL over SWL for stones less than $10 \mathrm{~mm}$, and the present review has not considered the substantial role of ureteroscopy for addressing stones less than $20 \mathrm{~mm}$ in diameter, regardless of location.

\section{Hydronephrosis}

Hydronephrosis is another important factor to consider when choosing SWL or PNL. Hydronephrosis may be an indicator of an underlying abnormality such as UPJ obstruction. In the setting of a renal pelvic calculus with apparent UPJ obstruction, it is difficult to determine whether the UPJ obstruction preceded the stone or whether the stone has caused edema at the UPJ which will resolve subsequent to removal of the stone. Nevertheless, there is ample evidence to suggest that PNL provides superior stone-free rates in cases associated with hydronephrosis. Winfield et al. noted a stone-free rate of $53 \%$ following SWL for staghorns in hydronephrotic systems compared to $70 \%$ for staghorns in normal systems (13). Meretyk et al. noted a $26 \%$ SFR in patients undergoing SWL monotherapy for staghorns in hydronephrotic systems, compared to $80 \%$ for similar patients who had PNL instead (15). In patients with renal stones associated with hydronephrosis secondary to obstruction of a ureteroenteric diversion, SWL renders the kidney stone free in only $25 \%$ to $75 \%$ of cases, in comparison to PNL, which results in clearance $60 \%$ to $100 \%$ of the time (22). SWL is contraindicated in cases in which there is obstruction distal to the stone.

\section{Calyceal Diverticulum}

A calyceal diverticulum is an outgrowth of a calyx which communicates with the rest of the

Table 2 - Comparison of stone-free rates for lower pole calculi, shock wave lithotripsy versus percutaneous nephrolithotomy.

\begin{tabular}{lccc}
\hline Stone Size & Shock Wave & $\begin{array}{c}\text { \% Stone-Free } \\
\text { PNL }\end{array}$ & p-value \\
\hline $1-10 \mathrm{~mm}$ & $63 \%$ & $100 \%$ & 0.003 \\
$11-20 \mathrm{~mm}$ & $23 \%$ & $93 \%$ & 0.001 \\
$21-30 \mathrm{~mm}$ & $14 \%$ & $86 \%$ & 0.029 \\
\hline
\end{tabular}

Adapted from Albala et al: J Urol (2001) 166:2072-2080. PNL, percutaneous nephrolithotomy. 
collecting system through a narrow channel. Stones may form in these structures as result of urinary stasis in the diverticulum. Stones in calyceal diverticula may be approached with SWL, PNL, ureteroscopy, or laparoscopy. Stone-free rates for SWL of calyceal diverticular stones are quite low, on average less than $25 \%$, and shock wave has the disadvantage of not being able to get rid of the diverticulum itself. Nevertheless, symptomatic relief, at least in the short term, occurs in upwards of $70 \%$ of patients undergoing SWL for calyceal diverticular stones. SWL therapy for calyceal diverticular stones may be considered in select patients with stones less than $1.5 \mathrm{~cm}$ and a diverticular neck which is shown to be short and patent on radiography. Yet, even in this group of patients, stone-free rates barely approach $60 \%$ (23). The authors of the present review question whether diverticula with short, patent necks and good drainage really exist.

Although more invasive, a percutaneous approach allows direct access to the inside of the diverticulum, facilitates stone removal, and allows the urologist to dilate or incise the neck and fulgurate the wall of the diverticulum. Stone-free rates following PNL of calyceal diverticular stones range from $77 \%$ to $100 \%$ and resolution of the diverticulum occurs in an average of $78 \%$ of cases.

\section{Renal Anomalies}

Renal calculi may occur in horseshoe kidneys as well as pelvic kidneys, owing to the relatively high ureteral insertion in the former and the malrotation often seen in the latter, both of which may result in urinary stasis. SWL can be used to treat stones in both horseshoe and ectopic kidneys, but stone localization may be more difficult.

In order to perform PNL in pelvic kidneys, a laparoscopic-assisted transperitoneal approach, with various modifications, has been described (24-26). However, due to the relative difficulty of accessing the collecting system of a pelvic kidney percutaneously, SWL should be the initial approach to stones in this situation, despite the relatively poor results. Kupeli et al. reported a $54 \%$ stone-free rate following SWL therapy to stones in pelvic kidneys
(27). Patient positioning is a key factor in SWL in pelvic kidneys. The patient may be positioned supine if the bony pelvis does not hinder delivery of shock waves to the target; otherwise, the prone position should be used. A similar prone approach may be taken with a patient who has a stone in a transplant kidney.

In horseshoe kidneys, the position of the collecting system may not allow for adequate visualization of the stone, nor for satisfactory stone clearance after SWL, especially from the lower calyces. Stone-free rates following SWL in horseshoe kidneys range from $54 \%$ for lower pole calculi to $100 \%$ for middle and upper calyceal stones (28). Kirkali et al. found that stones $>10 \mathrm{~mm}$ fare poorly (SFR of 28\%) (29). Furthermore, there tends to be a very high recurrence rate in patients with horseshoe kidneys who are not rendered stone-free (30).

As an alternative, PNL can be readily performed in horseshoe kidneys, because their position, with the upper pole more posterior and lateral, facilitates percutaneous puncture. However, if the approach is to a lower calyx the risk of bowel injury is higher. Stone-free rates range for PNL in horseshoe kidneys range from $75 \%$ to $100 \%(31,32)$. In summary, SWL should be the first line therapy for most stones in pelvic kidneys. In horseshoe kidneys, SWL may be used for stones less than or equal to 10 $\mathrm{mm}$ in the middle or upper pole, and the kidney should have good drainage documented radiographically. Otherwise, PNL or ureteroscopy are the treatments of choice.

\section{Renal Cysts}

Renal cystic disease may cause distortion of the collecting system which can adversely affect stone clearance after SWL. Deliveliotis et al. performed SWL in 15 patients with large (mean size 5 $\mathrm{cm}$ ), distorting renal cysts but normal renal function. The mean stone size was $1 \mathrm{~cm}$, and despite a $100 \%$ fragmentation rate, only $60 \%$ of patients were stone free at one month follow-up. The SFR in patients with polycystic kidney disease was $25 \%$ compared to $73 \%$ in patients who only had simple cysts (33). 


\section{SPECIAL CIRCUMSTANCES}

\section{Solitary Kidney and Renal Insufficiency}

Both SWL and PNL are known to produce short-term renal injury. The question therefore arises whether either of these modalities has significant deleterious effects in patients with only one kidney.

In 1990, Brito et al. reported 5 year follow up of 8 patients with solitary kidneys treated with SWL (34). The mean serum creatinine in these patients rose significantly, from $1.53 \mathrm{mg} / \mathrm{dl}$ pre-SWL to $2.31 \mathrm{mg} / \mathrm{dl}$ at 5 years post-treatment. The small number of patients in this study, as well as the fact that some degree of renal insufficiency was present prior to SWL in some of the patients (as indicated by the elevated mean creatinine level for the cohort prior to treatment), may have biased this study. Chandhoke et al. compared long-term renal function in 31 patients with solitary kidneys with or without renal insufficiency following SWL or PNL (35). In patients with a solitary, normally-functioning kidney, deterioration in renal function (defined as at least a $20 \%$ decrease in glomerular filtration rate, GFR) was seen in $22 \%$ of SWL patients and in $29 \%$ of PNL patients. In patients with 1 or 2 kidneys and moderate renal insufficiency (serum creatinine $2 \mathrm{mg} / \mathrm{dl}$ to 3 $\mathrm{mg} / \mathrm{dl}$ ) prior to treatment, no long-term deterioration in GFR was seen after either SWL or PNL. In patients with 2 kidneys but serum creatinine over 3 $\mathrm{mg} / \mathrm{dl}$, long-term deterioration in GFR was seen in all 4 patients who underwent SWL, while the only patient in this group who underwent PNL showed no decrease in GFR. This study concluded that SWL and PNL were equally safe in patients with solitary kidneys and normal renal function and in patients with 2 kidneys and mild renal insufficiency, and that the choice of procedure in these patients should be determined by stone factors (size, composition, location, etc.) rather than on renal function or the presence of a solitary kidney. More recently, Liou \& Streem compared the long-term effects of SWL, PNL, and combination therapy in patients with solitary kidneys and found no evidence of renal deterioration in any of the treatment arms, even in patients with a pre-treatment serum creatinine higher than $2 \mathrm{mg} / \mathrm{dl}$ (36). Thus, it appears that both SWL and PNL may be safely performed without untoward long-term effects on renal function either in patients with a solitary kidney or in patients with two normal kidneys.

\section{Obesity}

The morbidly obese patient with stone disease presents a therapeutic challenge. SWL may not be feasible if the patient is too heavy for the gantry or table. The distance from the patient's skin to the stone may be longer than the focal length of the lithotriptor. Therefore, the machine used for SWL in obese patients should have a long focal length and should be able to generate a high peak pressure. Body mass index has been found to be an independent predictor of successful SWL, with a decreased chance of success in larger patients (37). In patients in whom stone factors do not mandate PNL, ureteroscopy may be a better choice than SWL.

Obesity may also pose a problem for patients in whom PNL is contemplated. A longer sheath and instruments may be necessary to traverse the distance to the kidney. If necessary, stay sutures may be placed on the end of the working sheath in order to allow it to be advanced deeper into the abdominal wall, thereby bridging the gap to the kidney. The most significant consideration in obese patients is the potential morbidity of prolonged general anesthesia in the prone position. Morbidly obese patients often have other significant comorbidities, such as hypertension, diabetes mellitus, cardiovascular disease, and pulmonary restrictive disease, all of which increase the risk of general anesthesia. Despite this, most studies have failed to show any significant increase in complications or rates of transfusion in obese patients compared to their leaner counterparts $(38,39)$.

\section{EXTRACORPOREAL LITHOTRIPTORS}

The technologies used to fragment stones during PNL, namely ultrasonic and electrohydraulic lithotripsy, have changed little since their inception. Extracorporeal lithotriptors, on the other hand, have undergone significant modifications since the introduction in the early 1980s of the Dornier HM-3, 
especially with regard to down-sizing of the focal area in order to minimize collateral tissue damage. The proliferation of SWL machines over the past decade has made it difficult to compare outcomes because of the variety of machines in use; but in the opinion of many experts, the post-HM-3 modifications have only served to decrease the efficacy of stone fragmentation.

There appears to be no difference in fragmentation ability among the 3 basic types of lithotriptors currently available (electohydraulic, electromagnetic, and piezoelectric). A recent comparison of electrohydraulic (EH) and electromagnetic (EM) SWL machines at a single institution found a higher stone-free rate in patients treated with the $\mathrm{EH}$ unit than in those treated with the EM unit (77\% vs. $67 \%)$, despite a statistically larger stone burden in the former group. However, the patients treated with the $\mathrm{EH}$ device required a greater number of auxiliary procedures, so that the efficiency quotients of the two machines were comparable in the end (40). Bierkens et al., in a multi-institutional trial of five different $2^{\text {nd }}$-generation lithotriptors, found a stone-free rate of only $45 \%$, with $20 \%$ of cases requiring re-treatment. There was no significant difference in stone-free rates among the lithotriptors included in the study (41).

Teichman et al. recently tested 7 different lithotriptors in vitro against pure stones composed of COM, cystine, brushite, and struvite ranging in size from 1 to $3 \mathrm{~cm}$ (42). Mean fragment size and the mass of fragments larger than $2 \mathrm{~mm}$ were lowest for the Dornier HM-3, Storz Modulith SLX, and the Siemens Lithostar C, controlling for the total number of shocks. The Dornier Doli and Medispec Econolith produced the largest fragments. There was no correlation between mean fragment size and peak power at focal point F2 or with focal zone volume, although the latter parameters were not actually measured in the study but rather provided by the device manufacturers. As mentioned previously, the newer generation of lithotriptors has been designed with a narrow focus and large aperture in order to increase the energy delivered to the stone while minimizing exposure to surrounding structures (43). Overall, however, it appears that the radical reduction in focal area of lithotriptors subsequent to the HM-3 has not resulted in any significant improvement in fragmentation ability in these newer devices (42). The model of lithotriptor available to the urologist should therefore also be a consideration when determining treatment modality.

\section{MORBIDITY AND COMPLICATIONS}

Although the morbidity of SWL and PNL is much less than that seen with open stone surgery, significant complications may be associated with both. Proper patient selection and appropriate technique are essential in order to minimize complications from either approach.

\section{Percutaneous Nephrolithotomy}

The morbidity of PNL is highly dependent on size of the stone. Although injuries associated with obtaining percutaneous access may occur regardless of the size of the stone, stone burden still plays a role in the rate of access-related injuries because larger stones often require multiple punctures. The morbidity of treating a moderate-sized calculus through a single subcostal puncture is actually quite low. The reader should keep in mind that much of the data on PNL complications presented in large series reflects the relatively numerous staghorn and other complicated stones which are treated at tertiary referral centers.

In a review by Lee et al. of 500 patients undergoing PNL, the most common complications were bleeding necessitating transfusion (12\%) and pulmonary problems (7\%) (44). The majority of bleeding incidents $(88 \%)$ in this series occurred at the time of, or immediately following, the procedure, and the remainder were delayed and due to pseudoaneurysm formation. Arteriovenous malformations can also cause delayed bleeding after PNL. Transfusion rates after PNL range between 3\% and $23 \%$ overall $(45,46)$. The transfusion rate tends to increase with larger stone burdens and use of multiple access tracts. Persistent bleeding refractory to placement of a nephrostomy tube can be managed with angiography and selective embolization. Contemporary methods of super-selective angioinfarction makes significant renal parenchymal loss in these situations highly unlikely (47). 
The pleura is the most common adjacent structure to be injured. Pleural complications (effusions, pneumothorax, hydrothorax) are much more likely when supracostal access is used. The rate of pleural complications ranges from 0 to $37 \%$. Of these, however, only a minority ( 0 to $8 \%$ ) require treatment with placement of a chest tube (48-51). Nevertheless, supracostal puncture undoubtedly presents increased morbidity for the patient compared to an infracostal approach, and the authors recommend supracostal access only when absolutely necessary. Upper pole access can also be safely achieved through an infracostal approach by advancing the needle cephalad under the $12^{\text {th }} \mathrm{rib}$, although this technique is more challenging as it requires directing the needle in three axes rather than two (52).

Although any organ adjacent to the kidney may be injured during PNL, most such complications are quite rare and can be managed conservatively. Perforation of the colon occurs in less than $1 \%$ of cases (53) and can usually be managed by withdrawing the tip of the nephrostomy tube into the colon and placing a double-pigtail stent into the ureter. Injuries to the spleen and liver are extremely rare if these organs are of normal size.

Perforation of the renal pelvis is not uncommon, but usually is readily managed with
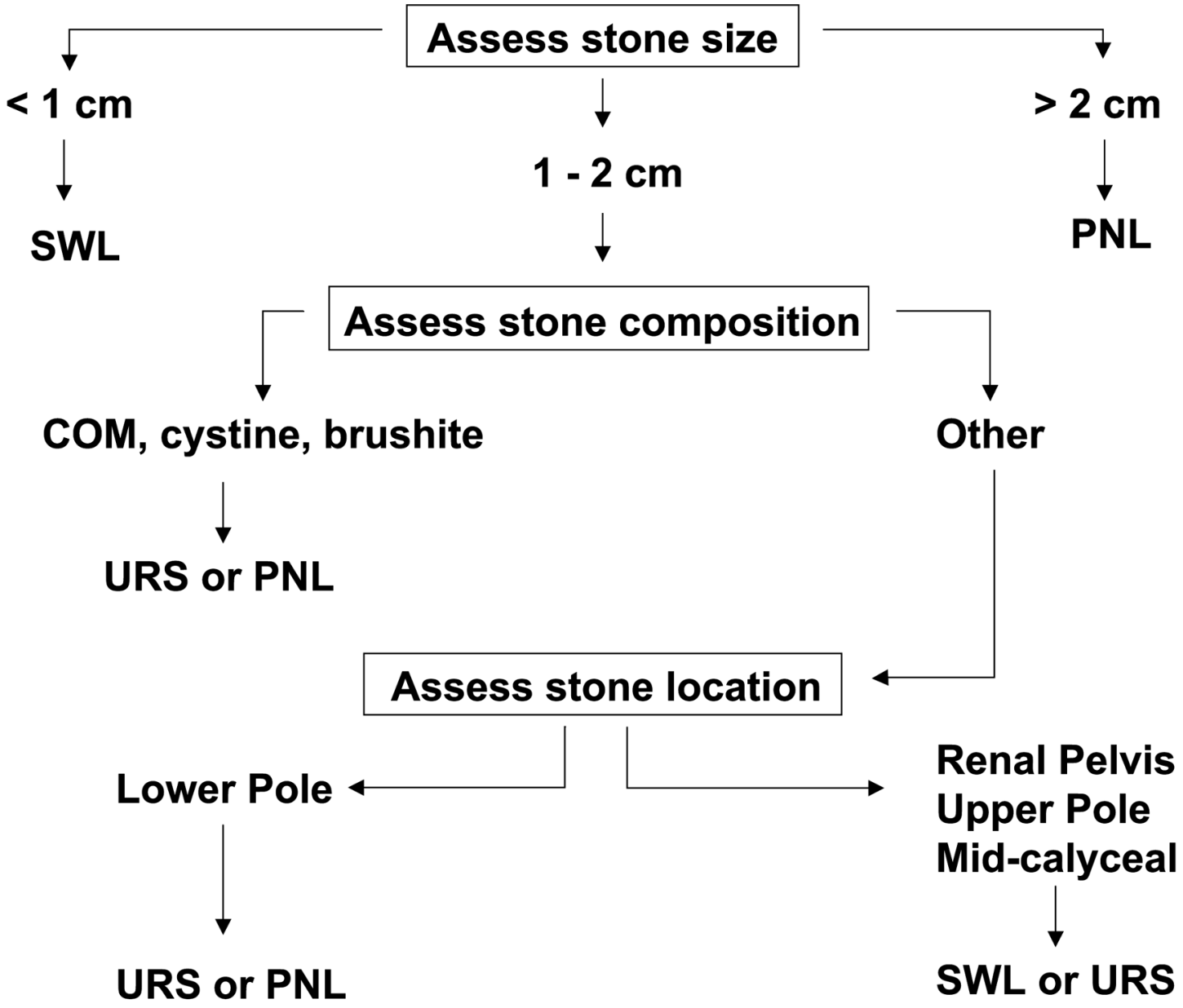

Figure 1 - Algorithm for a rational approach to contemporary management of renal calculi. 
nephrostomy tube drainage. A nephrostogram to rule out extravasation is mandatory prior to tube removal in order to avoid a urine leak.

Finally, despite the routine use of perioperative antibiotics, sepsis has been reported to occur in $0.25 \%$ to $1.5 \%$ of patients undergoing PNL $(45,54)$.

\section{Shockwave Lithotripsy}

The most common serious complication following SWL is steinstrasse, which generally occurs in less than $10 \%$ of patients. The risk increases with larger stone burdens - in one study of 885 patients, steinstrasse occurred in $0.3 \%$ of stones less than 10 $\mathrm{mm}, 7 \%$ of stones between $10-20 \mathrm{~mm}$, and $11.5 \%$ of stones between $20-30 \mathrm{~mm}$ (55). In a recent series of 4,634 patients, multivariable analysis showed stone

Table 3 - Approaches to renal calculi in special situations.

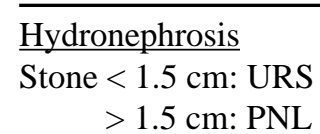

Calyceal Diverticulum

Stone $<1.5 \mathrm{~cm}$, upper pole: URS or PNL

$<1.5 \mathrm{~cm}$, lower pole: PNL

$>1.5 \mathrm{~cm}$ : PNL

$\underline{\text { Renal Anomalies }}$

1. Pelvic Kidney

Stone $<2 \mathrm{~cm}$ : SWL or URS

$>2 \mathrm{~cm}$ : URS or laparoscopic assisted PNL

2. Horseshoe Kidney

Stone < $1 \mathrm{~cm}$ : SWL

$1-2 \mathrm{~cm}$, in upper or mid calyx: SWL or URS

$1-2 \mathrm{~cm}$, in lower pole: PNL or URS

$>2 \mathrm{~cm}$ : PNL

Solitary Kidney

Select therapy based on stone factors.

Morbid Obesity

Stone $<1 \mathrm{~cm}$ : lithotriptor with adequate focal length?: SWL

1-2 cm: URS

$>2 \mathrm{~cm}:$ PNL size $>20 \mathrm{~mm}$ to be an independent predictor of steinstrasse, with a 3.7-fold increase in risk compared to smaller stones (56). Bilateral SWL performed at a single session is also a risk factor for steinstrasse (57). The incidence of steinstrasse after SWL of staghorn calculi approaches $50 \%$ and such stones should be considered a contraindication to the use of SWL (58). Placement of a ureteral stent prior to performing SWL has been advocated to prevent steinstrasse, but the discomfort and morbidity associated with stents preclude their use in routine cases. Pre-SWL placement of a ureteral stent is reasonable in patients with a solitary kidney.

Other possible complications of SWL include perirenal hematoma $(0.5 \%)$, fever $>39^{\circ} \mathrm{C}$ $(0.4 \%)$, and machine malfunction $(0.7 \%)$ (16). Renal colic is quite common (59) and pyelonephritis may also occur. Significant long-term effects of renal injury from SWL have not yet been shown to occur with any frequency; nevertheless, research into potential delayed effects of SWL, such as development or acceleration of hypertension, continues. Overall, SWL currently remains the least invasive, and probably the safest, modality of treating renal calculi.

\section{CONCLUSION}

This review has attempted to provide a rational guide to the selection of shock wave lithotripsy and percutaneous nephrolithotomy in contemporary management of renal calculi Obviously, each approach has its own advantages and disadvantages, and these need to be weighed carefully when choosing therapy. It should be emphasized that with the wide array of options (SWL, URS, PNL) available to treat stones today, routinely approaching stones with an "SWL challenge", without taking into account factors such as size, composition, location, etc., does not constitute standard of care.

Figure-1 provides an algorithm for a rational approach to surgical therapy of renal stones. Table-3 details options for management when faced with some of the special situations mentioned previously. It is hoped that by applying these principles, urologists 
will be able to optimize therapy for their patients, achieving the highest stone-free rates with the least degree of morbidity in the most efficient and costeffective manner possible.

$\overline{\text { Dr. Robert Marcovich is American Foundation }}$ for Urologic Disease Research Scholar

\section{REFERENCES}

1. Marcovich R, Smith AD: Renal calculi: practice and litigation patterns in perspective. AUA News. 2002; 7:34-6.

2. Newman DM, Scott JW, Lingeman JE: Two year follow up of patients treated with extracorporeal shock wave lithotripsy. J Endourol. 1988; 2:163-71.

3. Streem SB, Yost A, Mascha E: Clinical implications of clinically insignificant stone fragments after extracorporeal shock wave lithotripsy. J Urol. 1996; 155:1186-90.

4. Candau C, Saussine C, Lang H, Roy C, Faure F, Jacqmin D: Natural history of residual renal stone fragments after ESWL. Eur Urol. 2000; 37:18-22.

5. Zhong P, Preminger GM: Mechanisms of differing stone fragility in extracorporeal shockwave lithotripsy. J Endourol. 1994; 8:263-8.

6. Cranidis AI, Karayannis AA, Delakas DS, Livadas CE, Anezinis PE: Cystine stones: the efficacy of percutaneous and shock wave lithotripsy. Urol Int. 1996; 56:180-3.

7. Saw KC, Lingeman JE: Lesson 20 - management of calyceal stones. AUA Update Series. 1999; 20:1549.

8. Dretler SP, Polykoff G: Calcium oxalate stone morphology: fine tuning our therapeutic distinctions. J Urol. 1996: 155:828-33.

9. Bon D, Dore B, Irani J, Marroncle M, Aubert J: Radiographic prognostic criteria for extracorporeal shock wave lithotripsy: a study of 485 patients. Urology. 1996; 48:556-61.

10. Mostafavi MR, Ernst RD, Saltzman B: Accurate determination of chemical composition of urinary calculi by spiral computerized tomography. J Urol. 1998; 159:673-5.

11. Williams JC, Paterson RF, Kopecky KK, Lingeman JE, McAteer JA: High resolution detection of internal structure of renal calculi by helical computerized tomography. J Urol. 2002; 167:322-6.

12. Joseph P, Mandal AK, Singh SK, Mandal P, Sankhwar SN, Sharma SK: Computerized tomography attenuation value of renal calculus: can it predict successful fragmentation of the calculus by extracorporeal shockwave lithotripsy? A preliminary study. J Urol. 2002; 167:1968-71.

13. Winfield HN, Clayman RV, Chaussy CG, Weyman PJ, Fuchs GH, Lupu AN: Monotherapy of staghorn renal calculi: a comparative study between percutaneous nephrolithotomy and extracorporeal shock wave lithotripsy. J Urol. 1988; 139:895-9.

14. Streem SB, Yost A, Dolmatch B: Combination "sandwich" therapy for extensive renal calculi in 100 consecutive patients: immediate, long-term, and stratified results from a 10-year experience. J Urol. 1997; 158:342-5.

15. Meretyk S, Gofrit ON, Gafni O, Pode D, Shapiro A, Verstandig A et al.: Complete staghorn calculi: random prospective comparison between extracorporeal shock wave lithotripsy monotherapy and combined with percutaneous nephrostolithotomy. J Urol. 1997; 157:780-6.

16. Lingeman JE, Coury TA, Newman DM, Kahnoski RJ, Mertz JHO, Mosbaugh PG et al.: Comparison of results and morbidity of percutaneous nephrostolithotomy and extracorporeal shock wave lithotripsy. J Urol. 1987; 138:485-90.

17. Sampaio FJ, Aragao AH: Inferior pole collecting system anatomy: its probable role in extracorporeal shock wave lithotripsy. J Urol. 1992; 147:322-4.

18. Sampaio FJ, D'Anunciacao AL, Silva EC: Comparative follow-up of patients with acute and obtuse infundibulum-pelvic angle submitted to extracorporeal shockwave lithotripsy for lower caliceal stones: preliminary report and proposed study design. J Endourol. 1997; 11:157-61.

19. Sabnis RB, Naik K, Desai MR, Bapat SD: Extracorporeal shockwave lithotripsy for lower calyceal stones: can clearance be predicted? Br J Urol. 1997; 80:853-7.

20. Elbahnasy AM, Shalhav AL, Hoenig DM, Elashry OM, Smith DS, McDougall EM et al.: Lower caliceal stone clearance after shock wave lithotripsy or ureteroscopy: the impact of lower pole radiographic anatomy. J Urol. 1998; 159:676-82.

21. Albala DM, Assimos DG, Clayman RV, Denstedt JD, Grasso M, Gutierrez-Aceves J et al.: Lower pole I: a prospective randomized trial of extracorporeal shock 
wave lithotripsy and percutaneous nephrostolithotomy for lower pole nephrolithiasis - initial results. J Urol. 2001; 166:2072-80.

22. Wolf Jr. JS, Clayman RV: Percutaneous nephrostolithotomy. What is its role in 1997? Urol Clin N Am. 1997; 24:43-59.

23. Streem SB, Yost A: Treatment of caliceal diverticular calculi with extracorporeal shock wave lithotripsy: patient selection and extended follow-up. J Urol. 1992; 148:1043-6.

24. Eshghi AM, Roth JS, Smith AD: Percutaneous transperitoneal approach to a pelvic kidney for endourological removal of staghorn calculus. J Urol. 1985; 134:525-7.

25. Toth C, Holman E, Pazstor I, Khan AM: Laparoscopically controlled and assisted percutaneous transperitoneal nephrolithotomy in a pelvic dystopic kidney. J Endourol. 1993; 7:303-5.

26. Zafar FS, Lingeman JE: Value of laparoscopy in the management of calculi complicating renal malformations. J Endourol. 1996; 10:379-83.

27. Kupeli B, Isen K, Biri H, Sinik Z, Alkibay T, Karaoglan $\mathrm{U}$ et al.: Extracorporeal shockwave lithotripsy in anomalous kidney. J Endourol. 1999; 13:349-52.

28. Theiss M, Wirth MP, Frohmuller HG: Extracorporeal shock wave lithotripsy in patients with renal malformation. Br J Urol. 1993; 72:534-8.

29. Kirkali Z, Esen AA, Mugan MU: Effectiveness of extracorporeal shock wave lithotripsy in the management of stone-bearing horseshoe kidneys. J Endourol. 1996; 10:13-5.

30. Lampel A, Hohenfellner M, Schultz-Lampel D, Lazica M, Bohnen K, Thurof JW: Urolithiasis in hoseshoe kidneys: therapeutic management. Urology. 1996; 47:182-6.

31. Jones DJ, Wickham JEA, Kellett MJ: Percutaneous nephrolithotomy for calculi in horseshoe kidneys. J Urol. 1991; 145:481-3.

32. Al-Otaibi K, Hosking DH: Percutaneous stone removal in horseshoe kidneys. J Urol. 1999; 162:674-7.

33. Deliveliotis C, Argiropoulos V, Varkarakis J, Albanis S, Skolarikos A: Extracorporeal shock wave lithotripsy produces a lower stone-free rate in patients with stones and renal cysts. Int J Urol. 2002; 9:11-4.

34. Brito CG, Lingeman JE, Newman DM, Kight JL, Heck LL: Long-term follow-up of renal function in ESWLtreated patients with solitary kidney. J Urol. 1990; Suppl. 143:299A.

35. Chandhoke PS, Albala DM, Clayman RV: Long-term comparison of renal function in patients with solitary kidneys and/or moderate renal insufficiency undergoing extracorporeal shock wave lithotripsy or percutaneous nephrolithotomy. J Urol. 1992; 147:1226-30.

36. Liou LS, Streem SB: Long-term renal functional effects of shock wave lithotripsy, percutaneous nephrolithotomy and combination therapy: a comparative study of patients with solitary kidney. $\mathbf{J}$ Urol. 2001; 166:33-7.

37. Ackermann DK, Fuhrimann R, Pfluger D, Studer UE, Zingg EJ: Prognosis after extracorporeal shock wave lithotripsy of radio-opaque renal calculi: a multivariate analysis. Eur Urol. 1994; 25:105-9.

38. Carson CC, Danneberger JE, Weinerth JL: Percutaneous lithotripsy in morbid obesity. J Urol. 1988; 139:243-5.

39. Pearle MS, Nakada SY, Womack JS, Kryger JV: Outcomes of contemporary percutaneous nephrostolithotomy in morbidly obese patients. J Urol. 1998; 160:669-73.

40. Matin SF, Yost A, Streem SB: Extracorporeal shockwave lithotripsy: a comparative study of electrohydraulic and electromagnetic units. J Urol. 2001; 166:2053-6.

41. Bierkins AF, Hendrikx AJ, Dekort WJW, al e: Efficacy of second generation lithotriptors: a multicenter comparative study of 2206 extracorporeal shock wave lithotripsy treatments with the Siemens Lithostar, Dornier HM4, Wolf Piezolith 2300, Direx Tripter XI, and Breakstone lithotriptors. J Urol. 1992; 148:1052.

42. Teichman JMH, Portis AJ, Cecconi PP, Bub WL, Endicott RC, Denes B et al.: In vitro comparison of shock wave lithotripsy machines. J Urol. 2000; 164:1259-64.

43. Eisenmenger W, Du XX, Tang C, Zhao S, Wang Y, Rong F et al.: The first clinical results of "wide-focus and low-pressure" ESWL. Ultrasound in Med Biol. 2002; 28:769-74.

44. Lee WJ, Smith AD, Cubelli V, Vernace FM: Percutaneous nephrolithotomy: analysis of 500 consecutive cases. Urol Radiol. 1986; 8:61-6.

45. Segura JW, Patterson DE, LeRoy AJ, Williams HJ, Barrett DMB, R.C., May GR et al.: Percutaneous removal of kidney stones: review of 1000 cases. J Urol. 1985; 134:1077-81.

46. Stoller ML, Wolf Jr. JS, St Lezin MA: Estimated blood loss and transfusion rates associated with percutaneous nephrolithotomy. J Urol. 1994; 152:1977-81.

47. Jacobson AI, Amukele SA, Marcovich R, Shapiro O, 
Shetty R, Aldana JPA et al.: The efficacy and morbidity of therapeutic renal embolization in the spectrum of urologic disease. J Endourol. In press.

48. Young AT, Hunter DW, Castaneda-Zuniga WR, Hulbert JC, Lange P, Reddy P et al.: Percutaneous extraction of urinary calculi: use of the intercostal approach. Radiology. 1985; 154:633-8.

49. Picus D, Weyman PJ, Clayman RV, McClennan BL: Intercostal-space nephrostomy for percutaneous stone removal. AJR. 1986; 147:393-7.

50. Stening SG, Bourne S: Supracostal nephrolithotomy for upper pole calyceal calculi. J Endourol. 1998; 12:359-62.

51. Munver R, Delvecchio FC, Newman GE, Preminger GM: Critical analysis of supracostal access for percutaneous renal surgery. J Urol. 2001; 166:12426.

52. Niles BS, Smith AD: Techniques of antegrade nephrostomy. Atlas Urol Clin N Am. 1996; 4:1.

53. Neustein P, Barbaric ZL, Kaufman JJ: Nephrocolic fistula: a complication of percutaneous nephrostolithotomy. J Urol. 1986; 135:571-3.
54. Rao PN, Dube DA, Weightman NC, Oppenheim BA, Morris J: Prediction of septicemia following endourological manipulation for stones in the upper urinary tract. J Urol. 1991; 146:955-60.

55. Sayed MA-B, El-Taher AM, Aboul-Ella HA, Shaker SE: Steinstrasse after extracorporeal shockwave lithotripsy: aetiology, prevention, and management. BJU Int. 2001; 88:675-8.

56. Madbouly K, Sheir KZ, Elsobky E, Eraky E, Kenawy $M$ : Risk factors for the formation of a steinstrasse after extracorporeal shock wave lithotripsy: a statistical model. J Urol. 2002; 167:1239-42.

57. Weinerth JL, Flatt JA, Carson CC: Lessons learned in patients with large steinstrasse. J Urol. 1989; 142:14257.

58. Wirth MP, Theiss M, Frohmuller HG: Primary extracorporeal shock wave lithotripsy of staghorn renal calculi. Urol Int. 1992; 48:71-5.

59. Kupeli B, Biri H, Sinik Z, Karaca K, Tuncayengin A, Karaoglan U et al.: Extracorporeal shock wave lithotripsy for lower caliceal calculi. Eur Urol. 1998; 34:203-6.
Received: September 20, 2002 Accepted: October 10, 2002

\author{
Correspondence address: \\ Dr. Robert Marcovich \\ Department of Urology \\ Long Island Jewish Medical Center \\ 270-05, 76th Avenue \\ New Hyde Park, NewYork, 11040-1496, USA \\ Fax: + 1 718-343-6254 \\ E-mail: robertmarcovich@ hotmail.com
}

